\title{
KEMAMPUAN GURU DALAM IMPLEMENTASI PEMBELAJARAN DAN PENILAIAN HOTS PADA SISWA KELAS 4 SEKOLAH INDONESIA BANGKOK THAILAND
}

\author{
Erna Yayuk, Tyas Deviana, Nawang Sulistyani \\ FKIP Universitas Muhammadiyah Malang, Indonesia \\ Email: er_2y@yahoo.co.id
}

\begin{abstract}
ABSTRAK
Implementasi kurikulum 2013 menuntut guru untuk melakukan penilaian HOTS. Pada dasarnya penilaian HOTS harus diawali dengan pembelajaran yang HOTS juga. Hasil yang didapatkan berdasarkan pengamatan di SIB Thailand bawasannya masih ditemukan adanya (1) beberapa guru yang masih memerlukan updating tentang pengetahuan terutama kurikulum 2013, (2) kurang lebih 45\% siswa masih pasif ketika diajar dan keaktifan kelas sering didominasi oleh anak-anak yang pintar, (3) dalam proses pembelajaran soal-soal yang dibuat guru kebanyakan masih pada level C1-C3, dan (4) kemampuan siswa dalam berfikir kritis dan analitis sangat kurang. Berdasarkan analisis masalah tersebut, tujuan penelitian ini adalah untuk menganalisis dan mendeskripsikan kemampuan guru-guru dalam mengimplementasikan pembelajaran dan penilaian HOTS. Penelitian ini menggunakan pendekatan kualitatif. Subyek penelitian ini adalah guru kelas I sampai dengan VI SIB Bangkok Thailand. Teknik pengumpulan data yang digunakan yaitu: (1) teknik wawancara, (2) observasi dan (3) dokumentasi. Analisis data dalam penelitian ini mengacu pada analisis kualitatif yang dinyatakan oleh Milles dan Hubberman yaitu: (1) data reduction, (2) data display, (3) conclusion and verifying. Hasil penelitian menunjukkan bahwa kemampuan guru: (1) sudah mampu merancang perencanaan dan pembelajaran berbasis HOTS; (2) sudah terampil dalam memilih, memanfaatkan dan mengembangkan metode, model, media, sumber belajar yang mendukung tujuan pembelajaran berbasis HOTS, (3) guru sudah terampil dan memahami pengembangan dan penyusunan penilaian berbasis HOTS. Hal tersebut dibuktikan dengan beberapa indikator yaitu RPP disusun salah satunya dengan penggunaan kata operasional pada indikator sampai pada level C4-C6, pelaksanaan pembelajaran dengan menerapkan kecakapan abad 21 (komunikasi, kolaboratif, berfikir kritis dan menyelesaikan masalah, kreatif dan inovatif) dan soal-soal yang disusun sudah pada level C4-C6.
\end{abstract}

Kata kunci: HOTS; Pembelajaran; Penilaian

\begin{abstract}
The implementation of the 2013 curriculum requires teachers to conduct HOTS (Higher Order Thinking Skill) assessments. As requirement, the HOTS assessment must be based on HOTS learning. The data obtained from observations in the SIB Thailand region found (1) some teachers were still in need of updating their knowledge on the 2013 curriculum, (2) approximately $45 \%$ of students were still passive in learning activity and the class activity is often dominated by smart children, (3) in the process of learning, the questions made by teachers were still mostly at the C1-C3 level, and (4) students' abilities in critical and analytical thinking were lacking. Based on the analysis of the problem, the purpose of this research were to analyze and describe the ability of teachers to implement HOTS learning and assessment. This research employed qualitative approach. The subjects of this research were teachers of grades I through VI from SIB Bangkok, Thailand. The data collection techniques employed were: (1) interview techniques, (2) observation and (3) documentation. Data analysis in this research referred to the qualitative analysis stated by
\end{abstract}


Milles and Hubberman, namely: (1) data reduction, (2) data display, (3) conclusion and verifying. The results showed that the ability of teachers: (1) were already skilled in designing HOTS-based planning and learning; (2) already skilled in selecting, utilizing and developing methods, models, media, learning resources that support HOTS-based learning goals, (3) teachers are already skilled and understand the development and preparation of HOTS-based assessments. The result were proven by several indicators such as RPP (Lesson Plan) designed by using operational words on indicators up to the C4-C6 level, the implementation of learning by applying 21 st century skills (communication, collaborative, critical thinking and problem solving, creative and innovative) and questions arranged at the C4-C6 level.

Key words: HOTS; Learning; Assessment

\section{PENDAHULUAN}

Pemahaman guru terhadap konsep pembelajaran dan penilaian Higher Order Thinking Skills (HOTS) sangat diperlukan untuk mendukung implementasi kurikulum 2013. Menurut Retnawati (2018) tuntutan pada kurikulum 2013 bahwasanya peserta didik harus mampu berpikir tingkat tinggi. Kemampuan berpikir yang tidak hanya sekadar recall (mengingat), restate (menyatakan kembali), atau recite (merujuk tanpa melakukan pengolahan). Hal ini sejalan dengan pendapat Shidiq (2015) bahwa soal-soal HOTS merupakan instrumen pengukuran untuk mengukur kemampuan; (1) transfer suatu konsep ke konsep lainnya, (2) menerapkan dan memproses suatu informasi, (3) mencari keterkaitan dari berbagai informasi, (4) menggunakan informasi untuk menyelesaikan suatu masalah, dan (5) menelaah ide-ide secara kritis.

Berdasarkan praktik pembelajaran di lapangan, pembelajaran dan penilaian HOTS bukanlah suatu hal yang mudah diimplementasikan oleh para guru. Guru harus mampu menguasai konsep dan strategi pembelajarannya. Harapannya guru dapat menarik respon siswa agar lebih kritis dan pembelajaran lebih kondusif. Dengan demikian, kegiatan pembelajaran tidak lagi teacher centered melainkan student centered. Hal ini sejalan dengan tujuan pembuatan soal-soal HOTS yaitu untuk pembiasaan bagi peserta didik dalam mengerjakan standart olimpiade internasional serta meningkatkan kualitas soal.

Penyusunan soal-soal HOTS pada umumnya menggunakan stimulus. Stimulus merupakan landasan untuk membuat suatu pertanyaan. Dalam konteks HOTS, stimulus yang ditampilkan harus bersifat kontekstual dan menarik. Sumber stimulus tersebut dapat diperoleh dari isu-isu global seperti masalah pendidikan, teknologi informasi, sains, ekonomi, kesehatan dan infrastruktur Shidiq (2015). 
Dalam kaitannya soal HOTS, aspek pengetahuan (KI-3) diukur dengan tes, baik test lesan atau test tulisan. Tes lisan berupa pertanyaan yang telah disiapkan oleh guru dan dijawab oleh siswa. Test tulis tipe soal yang digunakan adalah pihan ganda dan uraian. Adapun karakteristik soal HOTS antara lain, (1) mengukur keterampilan berfikir tingkat tinggi, (2) berbasis permasalahan kontekstual, 3) menggunakan bentuk sal beragam, dan (4) mengukur level kognitif C-4 (menganalisis), C-5 (mengevaluasi), dan C-6 (mengkreasi).

Soal-soal HOTS pada konteks asesmen mengukur kemampuan : 1) transfer suatu konsep ke konsep lainnya, 2) memproses dan menerapkan informasi, 3) mencari kaitan dari berbagai informasi yang berbeda-beda, 4) menggunakan informasi untuk menyelesaikan masalah dan 5) menelaah ide dan informasi secara kritis (Kemendikbud, 2018).

HOTS (High Order Thinking Skills) atau keterampilan berpikir tingkat tinggi harus dibiasakan bagi peserta didik. Dinni (2018) mengemukakan bahwa seseorang dikatakan mampu menyelesaikan suatu masalah jika mampu menelaah suatu pemasalahan dan menggunakan pengetahuannya ke dalam situasi baru. Sesuai dengan pernyataan tersebut dapat disimpulkan bahwa dengan memiliki keterampilan berpikir tingkat tinggi dapat melatih siswa untuk menyelesaikan permasalahan yang dihadapi dengan arif dan bijaksana.

Beberapa hasil penelitian menunjukkan ternyata kualitas pendidikan masih lemah dengan ditandai oleh salah satu cirinya yaitu proses pendidikan yang memberikan sebanyak mungkin bahan pelajaran untuk mencapai target kurikulum, sedangkan kapasitas berpikir tidak ditingkatkan kepada tarap yang optimal (higher order thinking skills), Al Muhtar (2007); Abdul karim (2011). Data temuan lainnya menunjukan bahwa para guru memahami ada revisi dalam K 2013 diantaranya harus mengembangkan HOTS dalam kegiatan pembelajaran termasuk dalam pengembangan instrumen penilainnya, tapi mereka mengalami kesulitan dalam merumuskan Indikator yang ada dalam HOTS menjadi instrumen penilaian (Hanifah, 2019).

Berdasarkan hasil penelitian Yayuk, E., \& Ekowati (2016) pelaksanaan proses pembelajaran dan penilaian yang dilakukan guru-guru SIB Bangkok ditemukan adanya kurang lebih 45\% siswa masih pasif ketika diajar dan keaktifan

Erna Yayuk, Tyas Deviana, Nawang Sulistyani, Kemampuan Guru Dalam Implementasi Pembelajaran dan Penilaian HOTs Pada Siswa Kelas 4 Sekolah Indonesia Bangkok Thailand 
kelas sering didominasi oleh anak-anak yang pintar. Guru sudah berupaya berinovasi namun pembelajaran yang dilakukan belum sepenuhnya mencerminkan pembelajaran kecakapan abad 21. Dalam proses pembelajaran soal-soal yang dibuat guru 87\% masih pada level C1-C3. Hal ini menjadikan kemampuan siswa dalam berfikir kritis dan analitis sangat kurang.

Berdasarkan paparan di atas, maka diperlukan sebuah penelitian lanjut untuk memberikan suatu gambaran dan contoh pembelajaran dan penilaian HOTS. Hal ini diharapkan dapat memberikan inovasi pelaksanaan pembelajaran bagi guru SIB Thailand khususnya dalam pembelajaran dan penilaian HOTS dalam implementasi kurikulum 2013.

\section{METODE}

Pendekatan penelitian yang digunakan dalam penelitian ini adalah pendekatan deskriptif. Adapun jenis penelitian yang digunakan adalah penelitian kualitatif. Penelitian deskriptif kualitatif digunakan dengan tujuan untuk menganalisa fenomena yang terjadi di lapangan dengan pertimbangan bahwa masalah-masalah yang diteliti telah berlangsung pada masa sekarang.

Sumber data dalam penelitian ini diperoleh dari sumber data primer dan sumber data sekunder. Sumber data primer tersebut adalah guru dan siswa kelas IV SIB Thailand. Sedangkan sumber data sekunder diperoleh melalui studi observasi terhadap pelaksanaan pembelajaran dan dokumentasi yang meliputi penyusunan RPP, perangkat pembelajaran yang digunakan, foto kegiatan pembelajaran, serta data pendukung lainnya. Adapun prosedur penelitian yang dilakukan peneliti disajikan pada Gambar 1 berikut. 


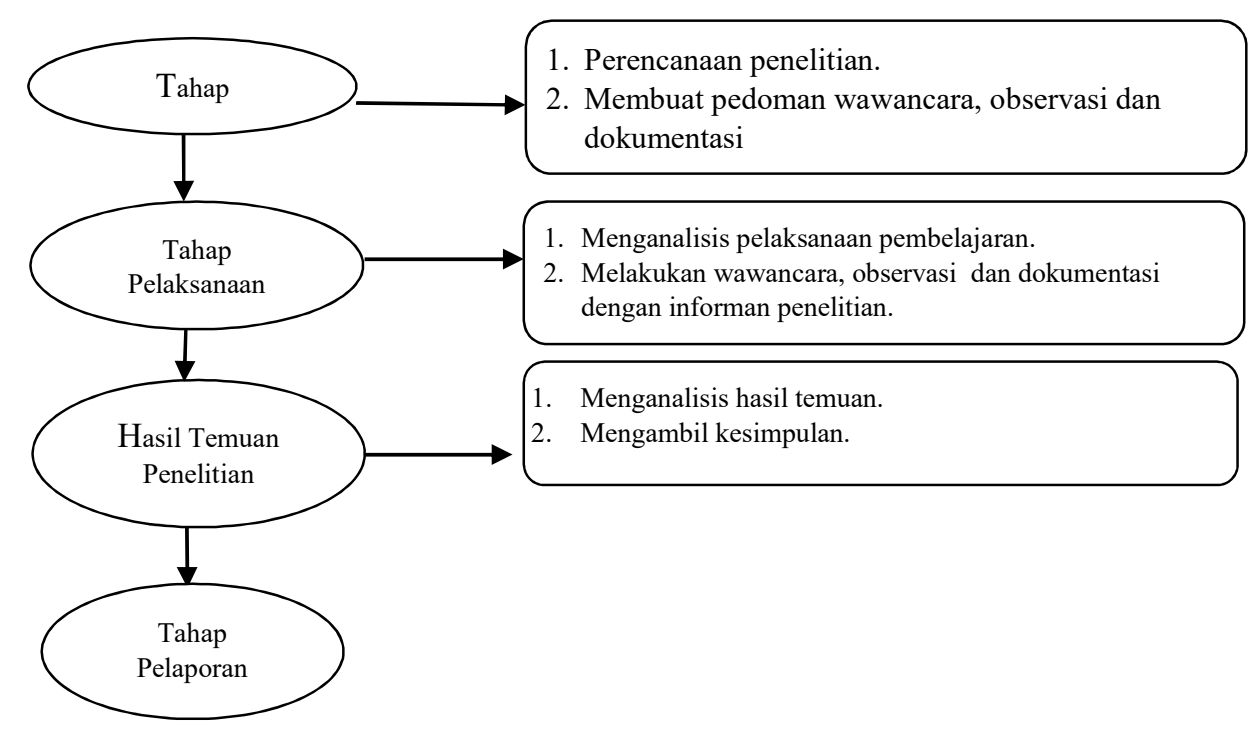

Gambar 1. Prosedur Penelitian

Ada 3 teknik pengumpulan data yang digunakan peneliti untuk memperoleh data di lapangan, yaitu: (1) teknik wawancara, (2) observasi dan (3) dokumentasi. Wawancara dilakukan kepada guru dan siswa kelas IV SIB Thailand untuk mengetahui tanggapan subjek penelitian terkait pelaksanaan pembelajaran dan penilaian HOTS yang telah dilakukan. Observasi pembelajaran dilakukan untuk melihat apakah pelaksanaan pembelajaran dan penilaian HOTS yang dilakukan oleh Guru sudah sesuia dengan rancangan pembelajaran yang telah dibuat. Dokumentasi ditujukan untuk mendapatkan data terkait dokumen rancangan pembelajaran, pelaksanaan pembelajaran, serta data pendukung lainnya. Analisis data dalam penelitian ini mengacu pada analisis kualitatif yang dinyatakan oleh Milles dan Hubberman. Adapun tahapan yang digunakan dalam melakukan analisis data yaitu: data reduction, data display, conclusion and verifying (Miles, Matthew B dan huberman, 1992).

\section{HASIL DAN PEMBAHASAN}

Hasil penelitian kemampuan guru dalam Implementasi Pembelajaran dan Penilaian HOTS pada Siswa Kelas 4 Sekolah Indonesia Bangkok Thailand akan diapaparkan sebagai berikut.

Erna Yayuk, Tyas Deviana, Nawang Sulistyani, Kemampuan Guru Dalam Implementasi Pembelajaran dan Penilaian HOTs Pada Siswa Kelas 4 Sekolah Indonesia Bangkok Thailand 


\section{Praktik Pembelajaran dan Penilaian HOTS}

Praktik pembelajaran dan penilaian HOTS dilaksanakan 2 kali yaitu pada kelas IV SD pembelajaran 1 dan pembelajaran 2 Tema Indahnya Kebersamaan sub tema Keberagaman Budaya Bangsaku. Berdasarkan pembelajaran yang dilaksanakan oleh guru dalam pembelajaran 1 dan pembelajaran 2, dapat disimpulkan bahwa pada pembelajaran dilakukan melalui 3 tahap yaitu perencanaan, pelaksanaan/implementasi, serta evaluasi dan refleksi pembelajaran. Adapun pembahasan tiap tahap kegiatan pembelajaran baik pembelajaran 1 dan pembelajaran 2 dapat dijelaskan sebagai berikut:

a. Perencanaan Pembelajaran

Sebelum memulai pembelajaran wajib membuat rencana pembelajaran yang mencakup pembelajaran dan penilaian HOTS. Rencana pembelajaran yang dibuat guru dimulai dari pembuatan matriks kompetensi dasar dan indikator yang menggunakan kata kerja operasional HOTS. Berdasarkan matriks yang sudah dibuat kemudian langkah selanjutnya malakukan identifkasi tujuan pembelajaran sesuai dengan dimensi kognitif yang menunjukkan level HOTS. Setelah matriks dan identifikasi indikator dan tujuan pembelajaran kemudian dibuatlah Rencana Pelaksanaan Pembelajaraan (RPP). Berikut salah satu hasil Indikator dan tujuan pembelajaran yang disusun guru pada RPP.

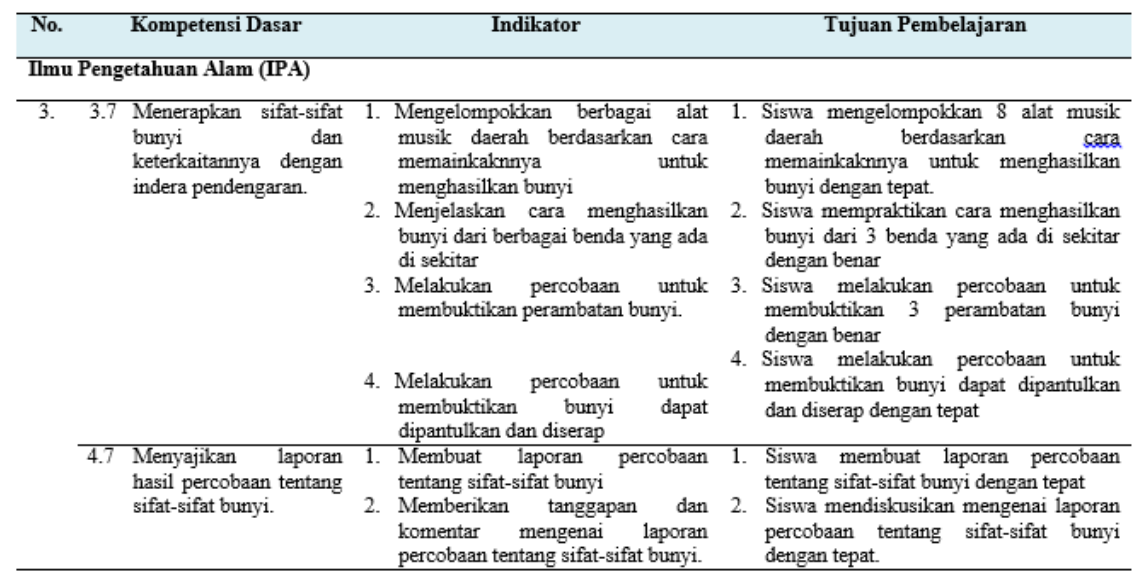

Gambar 2. KD, Indikator, dan Tujuan Pembelajaran pada RPP Guru

Berdasarkan rumusan indikator dan tujuan pembelajaran yang dibuat, guru mampu menyusun dan menguraikan indikator kognitif C3 (mengelompokkan dan memberikan tanggapan) serta indikator kognitif C6 (mempraktikkan dan membuat 
laporan). RPP yang dibuat untuk pembelajaran dan penilaian HOTS di Sekolah Indonesia Bangkok Thailand merupakan RPP lengkap yang dimulai dari langkah kegiatan, rangkuman materi, Lembar Kegiatan Siswa (LKS), media yang digunakan pada pembelajaran, soal evaluasi, dan penilaian (baik penilaian proses dan penilaian hasil). Majid (2014) menjabarkan komponen RPP menjadi 7 komponen, antara lain: 1) mencantumkan identitas, 2) mencantumkan tujuan pembelajaran, 3) mencantumkan materi pembelajaran, 4) mencantumkan model/metode pembelajaran, 5) mencantumkan langkah-langkah kegiatan pembelajaran, 6) mencantumkan media/alat/bahan/sumber belajar, dan 7) mencantumkan penilaian. Selain komponen RPP yang tercantum dalam Standar Proses tersebut, Trianto (2007) berpendapat bahwa komponen-komponen penting yang ada dalam RPP, meliputi: Standar Kompetensi (SK), Kompetensi Dasar (KD), hasil belajar, indikator pencapaian, strategi pembelajaran, sumber pembelajaran, alat dan bahan, langkah-langkah kegiatan pembelajaran, dan evaluasi.

RPP yang dibuat oleh guru dibuat selengkap mungkin untuk memudahkan guru dan siswa dalam belajar, selain itu agar tujuan pembelajaran dapat dicapai dengan maksimal. RPP yang lengkap yaitu dalam suatu RPP termuat semua komponen pendukung pembelajaran mulai dari identitas, indikator dan tujuan pembelajaran, langkah pembelajaran, model, metode dan strategi pembelajaran, sampai pada lampiran rangkuman materi, LKPD, soal evaluasi dan kunci jawaban, sampai pada penilaian. Hal ini sesuai dengan pendapat ahli, menurut pendapat Trianto (2007), rencana pelaksanaan pembelajaran yaitu panduan langkah-langkah yang akan dilakukan oleh guru dalam kegiatan pembelajaran yang disusun dalam skenario pembelajaran. RPP disusun untuk setiap pertemuan yang menjadi pedoman guru dalam pembelajaran. Berdasarkan Peraturan Menteri Pendidikan dan Kebudayaan No. 22 Tahun 2016 tentang Standar Proses Pendidikan Dasar dan Menengah disebutkan bahwa Rencana Pelaksanaan Pembelajaran (RPP) adalah rencana kegiatan pembelajaran tatap muka untuk satu pertemuan atau lebih. Sekolah Indonesia Bangkok di Thailand juga mengacu penuh pada pembelajaran yang ada di Indonesia, mulai dari kurikuler maupun ekstrakurikuler. RPP dikembangkan dari silabus untuk mengarahkan kegiatan pembelajaran siswa dalam

Erna Yayuk, Tyas Deviana, Nawang Sulistyani, Kemampuan Guru Dalam Implementasi Pembelajaran dan Penilaian HOTs Pada Siswa Kelas 4 Sekolah Indonesia Bangkok Thailand 
upaya mencapai Kompetensi Dasar (KD). RPP disusun berdasarkan KD atau subtema yang dilaksanakan tiap kali pertemuan atau lebih.

b. Pelaksanaan/Implementasi Pembelajaran

Pada tahap pelaksanaan pembelajaran, guru model melakukan dua kali pembelajaran, yaitu pada pembelajaran 1 dan pembelajaran 2 pada Tema Indahnya Kebersamaan sub tema Keberagaman Budaya Bangsaku. Pembelajaran dan penilaian HOTS perlu dilakukan karena jika menginginkan penilaian siswa yang HOTS maka diawali dengan pembelajaran yang HOTS juga. Tidak mungkin jika penilaian yang dilakukan merupakan penilaian HOTS, namun pembelajaran yang dilaksanakan pembelajaran LOTS (Low Other Thinking Skils).

Pembelajaran 1 dan pembelajaran 2 yang dilakukan oleh guru model di kelas IV SD Sekolah Indonesia Bangkok Thailand, dilakukan tidak hanya di dalam kelas namun juga di luar kelas.

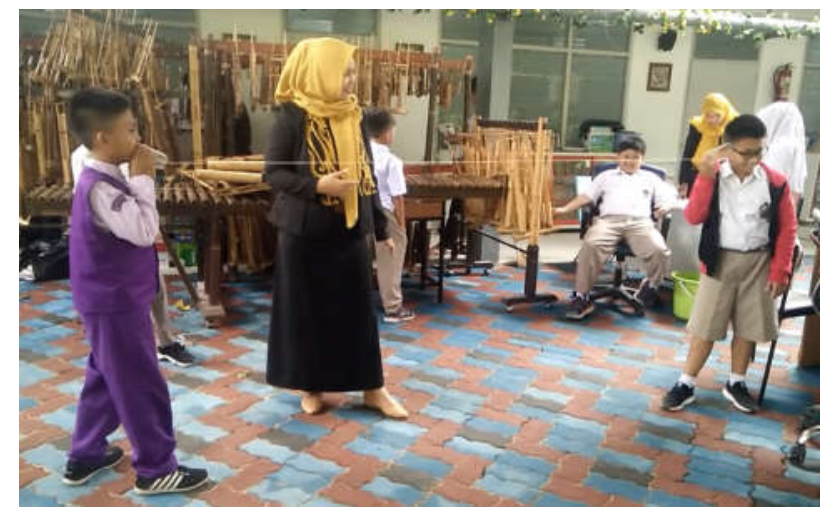

Gambar 3. Melakukan Percobaan Bunyi Berasal dari benda yang Bergetar

Berdasarkan gambaran pembelajaran tersebut siswa melakukan langsung percobaan tentang bunyi. Pembelajaran di luar kelas bertujuan agar pembelajaran memanfaatkan lingkungan sekitar siswa, sehingga dari siswa dekat dengan lingkungan serta memberikan pemahaman kepada siswa bahwa belajar tidak harus selalu di dalam kelas, bisa memanfaatkan lingkungan sekitar juga.

Hal tersebut sesuai dengan UU nomor 20 tahun 2003 tentang sistem pendidikan nasional, definisi "pembelajaran adalah proses interaksi peserta didik dengan pendidik dan sumber belajar pada suatu lingkungan belajar". Konsep pembelajaran menurut Corey (dalam Sagala, 2010) adalah suatu proses dimana 
lingkungan seseorang secara disengaja dikelola untuk memungkinkan ia turut serta dalam tingkah laku tertentu dalam kondisi-kondisi khusus atau menghasilkan respons terhadap situasi tertentu. Sedangkan Semiawan (2018) menuliskan bahwa pembelajaran adalah kegiatan guru secara terprogram dalam desain instruksional, untuk membuat siswa belajar secara aktif yang menekankan pada penyediaan sumber belajar.

Berdasarkan hasil penelitian yang sudah dipaparkan, diketahui bahwa dalam pembelajaran yang dilakukan oleh guru model menggunakan berbagai metode pembelajaran. Metode yang digunakan antara lain metode ceramah, metode diskusi kelompok, metode diskusi kelas, metode penugasan, metode praktikum dan unjuk kerja, dan lain-lain.

Berdasarkan observasi guru model dan observer, diketahui bahwa dengan adanya metode pembelajaran yang bervariasi membuat siswa antusias dalam belajar dan siswa tidak bosan dalam belajar. Hal tersebut diperkuat dengan pendapat Amri (2015) mengatakan, metode belajar mengajar adalah cara - cara yang dilakukan untuk menyampaikan atau menanamkan pengetahuan kepada subjek didik, murid, atau anak melaui sebuah kegiatan belajar mengajar, baik di sekolah, rumah, kampus, pondok, dan lain-lain.

Selain menggunakan metode pembelajaran yang bervariasi, guru juga menggunakan berbagai media dan sumber belajar yang bervariasi. Berdasarkan hasil yang telah dipaparkan diketahui bahwa media yang digunakan oleh guru model pada pembelajaran 1 dan pembelajaran 2 yaitu video, gambar, maupun benda-benda konkret. Media dan sumber belajar yang bervariasi memungkinkan siswa memiliki pengalaman belajar yang berbeda. Dengan adanya media dan sumber belajar tersebut diharapkan agar siswa mampu mencapai tujuan pembelajaran dengan maksimal. Pemilihan media yang sesuai dengan materi dan karakteristiktik siswa SD juga dapat menjadikan pembelajaran secara bermakna. Siswa dapat diajak dengan melakukan berbagai eksperimen dengan berbantuan media mapun sumber belajar. Hal ini sesuai dengan pendapat Arsyad (2014) mengatakan bahwa media adalah komponen sumber sumber belajar atau wahana fisik yang mengandung materi instruksional di lingkungan siswa yang dapat merangsang siswa untuk belajar. Pendapat ini juga sejalan dengan Haryono (2014)

Erna Yayuk, Tyas Deviana, Nawang Sulistyani, Kemampuan Guru Dalam Implementasi Pembelajaran dan Penilaian HOTs Pada Siswa Kelas 4 Sekolah Indonesia Bangkok Thailand 
mengatakan media pembelajaran merupakan segala sesuatu yang dapat menyalurkan pesan, dapat merangsang pikiran, perasaan, dan kemauan siswa sehingga dapat mendorong terciptanya proses belajar untuk menambah informasi baru pada diri siswa. Berdasarkan uraian tersebut dapat disimpulkan bahwa media pembelajaran merupakan segala sesuatu yang dapat membantu penyampaian materi pembelajaran dari guru kepada siswa.

c. Penilaian Pembelajaran

Pada proses penilaian Guru telah membuat soal-soal yang dapat digunakan untuk mengukur level kognitif C4-C6.

\section{Kesimpulan:}

Berdasarkan hasil wawancara dengan teman dapat disimpulkan agama yang dianut oleh masyarakat Indonesia antara lain agama

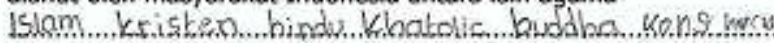

Indonesia terdiri atas banyak pulau, pulau di Indonesia antara lain .

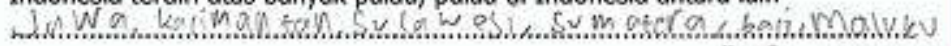

Suku bangsa di Indonesia sangat banyak antara lain suku

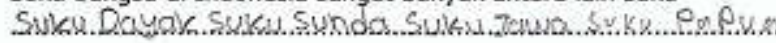

Papios irian jory.

Indonesia terdiri atas banyak pulau, suku bangsa, tarian, rumah adat, serta agama. Indonesia terdiri atas berbagai macam suku bangsa dan budaya, namun tetap dalam satu wadah Negara Kesatuan Republik Indonesia (NKRI). Keberagaman tersebut merupakan anugerah dari Tuhan Yang Maha Esa. Kito wajib mensyukurinya.

\section{Gambar 4. Hasil Lembar Kegiatan Peserta Didik}

Berdasarkan soal yang telah dibuat Guru, dapat dianalisis bahwa soal tersebut telah memenuhi unsur HOTS diantaranya dapat menggunakan informasi untuk menyelesaikan suatu masalah, mentransfer suatu konsep ke konsep lainnya, dan mencari hubungan dari berbagai informasi yang berbeda-beda.

Penilaian yang dilakukan tidak hanya penilaian hasil belajar namun juga penilaian proses belajar (Merta Dhewa, K., Rosidin, U., Abdurrahman, A., \& Suyatna, 2017). Penilaian proses dilaksanakan pada saat siswa melakukan berbagai kegiatan yang ada dalam LKS baik yang dilakukan secara individu maupun berkelompok. Sedangkan penilaian hasil belajar diperoleh dari penilaian soal 
evaluasi yang telah dikerjakan oleh siswa baik dalam pembelajaran 1 maupun pembelajaran 2 .

Penilaian pembelajaran perlu dilakukan karena dengan hasil penilaian siswa dapat mengetahui kekurangan dan kelebihannya dalam belajar selama ini. Menurut Widoyoko (2010) manfaat penilaian bagi siswa yaitu siswa dapat mengetahui sejauh mana telah berhasil mengkuti pembelajaran yang disampaikan oleh guru. Hasil yang diperoleh siswa dari penilaian meliputi dua kemungkinan yaitu memuaskan atau tidak memuaskan.

Berdasarkan praktik pembelajaran oleh guru model pada siswa kelas IV SD Sekolah Indonesia Bangkok Thailand diperoleh kesimpulan bahwa tujuan pembelajaran, proses pembelajaran, dan penilaian pembelajaran sangat berhubungan erat. Adapun hubungan ketiga komponen tersebut dapat dilihat sebagai berikut.

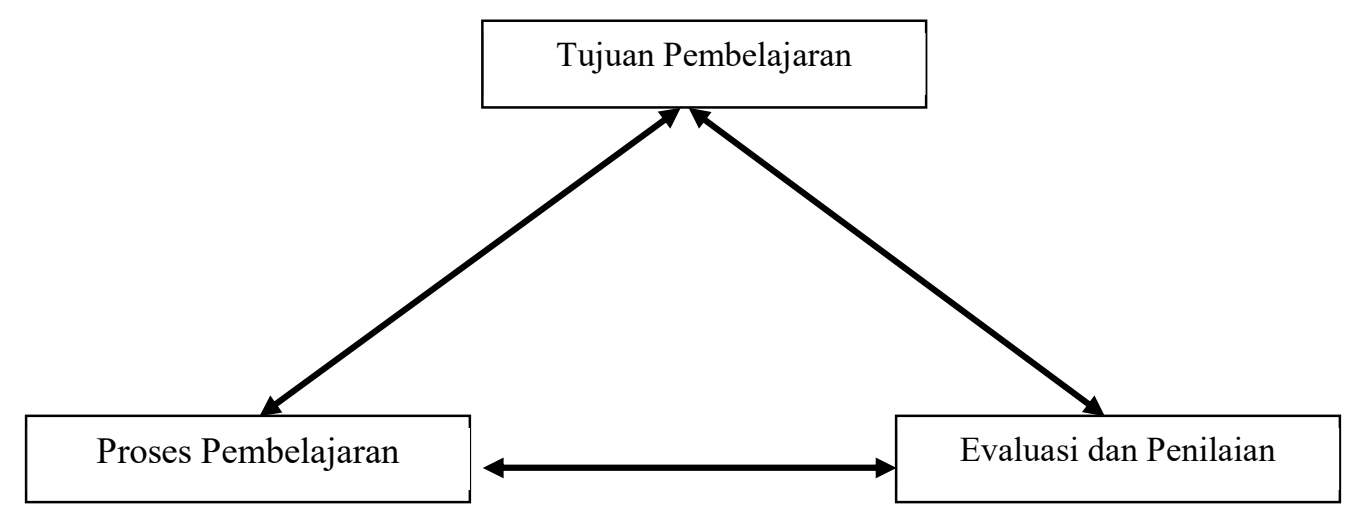

Gambar 1. Bagan Hubungan Tujuan Pembelajaran, Proses Pembelajaran, Serta Evaluasi dan Pembelajaran

Bagan hubungan ketiga komponen pembelajaran tersebut saling terkait dan saling keterhubungan. Makna dari penjelasan bagan tersebut akan dijelaskan sebagai berikut:

a. Hubungan tujuan pembelajaran dengan proses pembelajaran

Langkah-langkah kegiatan pembelajaran yang dituangkan dalam RPP harus sesuai dengan tujuan pembelajaran yang hendak dicapai. Begitu pula berdasarkan tujuan pembelajaran maka dikembangkan menjadi kegiatan proses pembelajaran. Berdasarkan bagan tersebut dapat disimpulkan bahwa

Erna Yayuk, Tyas Deviana, Nawang Sulistyani, Kemampuan Guru Dalam Implementasi Pembelajaran dan Penilaian HOTs Pada Siswa Kelas 4 Sekolah Indonesia Bangkok Thailand 
komponen tujuan pembelajaran dan penilaian terdapat tanda dua arah yang berarti saling terkait dan terhubung.

b. Hubungan tujuan pembelajaran dengan evaluasi dan penilaian

Tujuan pembelajaran digunakan sebagai dasar untuk melaksanakan evaluasi dan penilaian. Dari tujuan pembelajaran yang telah ditetapkan maka dapat ditentukan jenis penilaian yang sesuai, baik penilaian tes maupun non tes. Begitu pula dengan evaluasi dan penilaian harus dikembangkan berdasarkan tujuan pembelajaran. Proses penilaian dapat melihat ketercapaian siswa dalam mencapai tujuan pembelajaran. Dapat disimpulkan bahwa tujuan pembelajaran serta evaluasi dan penilaian mempunyai hubungan saling keterkaitan.

c. Hubungan antara proses pembelajaran dengan evaluasi dan penilaian

Proses pembelajaran tidak terlepas dari penilaian. Suatu proses pembelajaran di dalamnya memuat kegiatan pembelajaran yang menuju pada penilaian pembelajaran. Penilaian yang dibuat oleh guru harus mengacu pada proses pembelajaran yang dilaksanakan. Misalnya jika proses pembelajaran menitiberatkan pada ranah psikomotorik, maka penilaian yang dibuat harus dapat menilai keterampilan siswa.

\section{Evaluasi dan Refleksi}

Setelah melaksanakan praktik mengajar di kelas IV SD Sekolah Indonesia Bangkok Thailand, maka perlu diadakan evaluasi dan refleksi. Evaluasi dan refleksi dilakukan oleh semua pihak dari Prodi PGSD yang terlibat dalam pembelajaran, guru baik wali kelas IV maupun guru SIB lainnya, dan juga Kepala Sekolah Indonesia Bangkok Thailand. Evaluasi dan monitoring perlu dilakukan agar guru model mendapatkan umpan balik terhadap pembelajaran yang telah dilaksanakan. Berdasarkan hasil evaluasi dan monitoring diperoleh beberapa komentar dan tanggapan sebagai berikut.

a. Pembentukan kelompok sudah heterogen baik dari segi gender dan kemampuan, sehinngga terlihat dalam pembelajaran siswa yang 
berkemampuan tinggi selalu memberi motivasi positif kepada temannya yang belum bisa.

b. Pelaksanaan pembelajaran terlihat siswa antusias dalam kegiatan belajar di LKS karena siswa melakukan berbagai macam kegiatan yang menantang bagi siswa.

c. Media yang digunakan dalam pembelajaran bervariasi sehingga anak tertarik untuk ikut pembelajaran, mulai dari video, gambar, dan melakukan kegiatan langsung.

Dalam kegiatan evaluasi dan monitoring, terdapat beberapa masukan sebagai refleksi pembelajaran. Adapun saran yang diperoleh antara lain:

a. Dalam pembelajaran reward verbal yang diberikan oleh guru model intensitasnya masih kurang, masih perlu ditambahkan untuk dapat memotivasi siswa lebih giat lagi dalam belajar.

b. Guru model dalam pembelajarn terlihat 2 atau 3 kali memberikan pertanyaan dengan jawaban serentak, namun pada masuk kegiatan inti dan kegiatan penutup sudah tidak terlihat.

c. Pemberian penguatan pada jawaban siswa yang benar lebih ditingkatkan agar siswa tahu mana jawaban yang benar dan bagaimana yang salah.

Berdasarkan hasil evaluasi dan refleksi diperoleh kesimpulan bahwa pembelajaran dan penilaian HOTS yang dilakukan oleh guru sudah sangat baik, hal ini ditunjukkan berdasarkan kesesuaian antara Rencana Pelaksanaan Pembelajaran dan Implementasi Pembelajaran meningkat dari pembelajaran sebelumnya. Pembelajaran dan penilaian HOTS dapat dilihat dari perangkat pembelajaran yang disusun, praktik pembelajaran yang telah dilaksanakan, serta penilaian yang dilakukan. Adapun indikator keberhasilan pembelajaran dan penilaian HOTS diantaranya yaitu; (1) tersusunnya indikator pembelajaran pada level kognitif C4C6, (2) kegiatan pembelajaran yang dapat mentransfer suatu konsep ke konsep lainnya, dan (3) evaluasi pembelajaran yang memuat soal-saoal HOTS.

Menurut Abdullah, Abidin, \& Ali (2015) evaluasi adalah suatu proses yang sistematis untuk menentukan atau membuat keputusan sejauh mana tujuan-tujuan pembelajaran dicapai oleh siswa. Inti dari kegiatan evaluasi yaitu adanya pengambilan keputusan, dan obyek dari evaluasi yaitu program pembelajaran.

Erna Yayuk, Tyas Deviana, Nawang Sulistyani, Kemampuan Guru Dalam Implementasi Pembelajaran dan Penilaian HOTs Pada Siswa Kelas 4 Sekolah Indonesia Bangkok Thailand 
Sehingga evaluasi bertujuan untuk mendapatkan informasi tentang efektivitas program pembelajaran. Evaluasi pembelajaran yaitu evaluasi program pengambilan keputusan yang diperoleh dari hasil asesmen terhadap kegiatan belajar siswa yang dilakukan melalui proses pembelajaran. Proses evaluasi pembelajaran akan menjadi lebih baik, lebih demokratis, bila melibatkan rekan staf pendidik yang handal, manajemen sekolah dan pihak orang tua.

\section{SIMPULAN}

Adapun kesimpulan pada penelitian kemampuan guru dalam implementasi pembelajaran dan penilaian HOTS di Sekolah Indonesia Bangkok Thailand adalah sebagai berikut: Guru sudah terampil dalam merancang perencanaan dan pembelajaran berbasis HOTS. Hal ini dibuktikan dengan indikator bahwa dalam penyusunan RPP kata operasional yang digunakan sudah mengacu pada pada tingkatan kognitif C-4 sampai C-6. Guru merencanakan dengan pemilihan model pembelajaran yaitu PBL. Langkah-langkah pembelajaran yang dikembangkan juga mengajak anak untuk berfikir tingkat tinggi, bekerja ilmiah dengan mengikuti sintak pembelajaran yang telah direncanakan. Guru sudah terampil dalam memilih, memanfaatkan dan mengembangkan metode, model, media, sumber belajar yang mendukung tujuan pembelajaran berbasis HOTS. Pemilihan media dan sumber belajar ini tentunya juga disesuaikan dengan materi dan karakteristik siswa. Dengan demikian pembelajaran yang dilakukan bermakna karena siswa belajar dengan mengkontruksi pemahamannya sendiri dan berdasarkan pengalamn yang diperoleh sebelumnya. Guru sudah terampil dan memahami pengembangan dan penyusunan penilaian berbasis HOTS. Adapun soal HOTS yang telah disusun telah memenuhi indikator (1) mengukur keterampilan berfikir tingkat tinggi, (2) berbasis permasalahan kontekstual, 3) menggunakan bentuk soal beragam, dan (4) mengukur level kognitif C-4 (menganalisis), C-5 (mengevaluasi), dan C-6 (mengkreasi

\section{DAFTAR PUSTAKA}

Abdul karim, M. (2011). Pendidikan Matematika 2. Jakarta: Universitas Terbuka. Abdullah, A. H., Abidin, N. L. Z., \& Ali, M. (2015). Analysis of Students' Errors 
in Solving Higher Order Thinking Skills (HOTS) Problems for the Topic of Fraction. Asian Social Science, 11(21), 133. https://doi.org/10.5539/ ass.v $1 \ln 21 \mathrm{p} 133$

Al Muhtar. (2007). Model Pembelajaran IPS. Bandung: SPS UPI.

Amri, S. (2015). Pengembangan dan Model Pembelajaran dalam Kurikulum 2013. Jakarta: Prestasi Pustaka.

Arsyad, A. (2014). Media Pembelajaran. Jakarta: Raja Grafindo Persada.

Dinni, H. N. (2018). HOTS (High Order Thinking Skills) dan kaitannya dengan kemampuan literasi matematika. In PRISMA, Prosiding Seminar Nasional Matematika, Vol. 1, pp. 170-176.

Hanifah, N. (2019). Pengembangan instrumen penilaian Higher Order Thinking Skill (HOTS) di sekolah dasar. In Current Research in Education: Conference Series Journal, 1(1), 005.

Haryono, A. D. (2014). Metode praktis Pengembangan Sumber dan Media Pembelajaran. Malang: Genius Meida dan Pustaka Inspiratif.

Majid, A. (2014). Pembelajaran Tematik Terpadu. Bandung: Rosdakarya.

Merta Dhewa, K., Rosidin, U., Abdurrahman, A., \& Suyatna, A. (2017). The development of Higher Order Thinking Skill (Hots) instrument assessment in physics study. IOSR Journal of Research \& Method in Education (IOSRJRME), 07(01), 26-32. https://doi.org/10.9790/7388-0701052632

Miles, Matthew B dan huberman, A. M. (1992). Analisis Data Kualitatif. Jakarta: universitas Indonesia Press.

Peraturan Menteri Pendidikan dan Kebudayaan No. 22 Tahun 2016 tentang Standar Proses Pendidikan Dasar dan Menengah.

Retnawati, H., Djidu, H., Apino, E., \& Anazifa, R. D. (2018). Teachers'knowledge About Higher-Order Thinking Skills And ITS Learning Strategy. Problems of Education in the 21st Century, 76(2), 215-230.

Sagala, S. (2010). Konsep dan Makna Pembelajaran untuk Membantu Memecahkan Problematika Belajar dan Mengajar. Bandung: Alfabeta.

Semiawan, C. (2018). Belajar dan Pembelajaran Prasekolah dan Sekolah Dasar. Jakarta: PT Macanan Jaya Cemerlang.

Erna Yayuk, Tyas Deviana, Nawang Sulistyani, Kemampuan Guru Dalam Implementasi Pembelajaran dan Penilaian HOTs Pada Siswa Kelas 4 Sekolah Indonesia Bangkok Thailand 
Shidiq, A. S., Masykuri, M., \& VH, E. S. (2015). Analisis higher order thinking skills (HOTS) menggunakan instrumen two-tier multiple choice pada materi kelarutan dan hasil kali kelarutan untuk siswa kelas XI SMA N 1 Surakarta. In Prosiding SNPS (Seminar Nasional Pendidikan Sains), (Vol. 2, pp. 159166).

Trianto. (2007). Model Pembelajaran Terpadu dalam Teori dan Praktek. Jakarta: DEPDIKNAS.

Undang-Undang Nomor 20 tahun 2003 tentang Sistem Pendidikan Nasional.

Widoyoko, E. P. (2010). Evaluasi Program Pembelajaran Panduan Praktis bagi Pendidik dan Calon Pendidik. Yogyakarta: Pustaka Pelajar.

Yayuk, E., \& Ekowati, D. W. (2016). The Quality Improvement Of The Learning Process Of Mathematics Using Indonesian Cultures In Lesson Study At The Indonesian Elementary School In The Indonesian Embassy Bangkok Thailand. University of Muhammadiyah Malang 